\title{
Discussion on the Construction of Spiritual Civilization in Universities Based on Volunteer Service
}

\author{
Yanpeng Gao
}

Female, Sep. 10th ,1985; Jia xian,Yulin city,Shaanxi province ;Han; Yulin University, Master degree; Lecturer;Ideology and politics

\begin{abstract}
The acceleration of the reform process of higher education has made people require students to pay more attention to their ideological and moral level, behavioral awareness and spiritual civilization construction while requiring students to quickly improve their learning quality. Therefore, how to enable students to achieve better development has become a large number of people. Problems that teachers in colleges and universities focus on solving. This article starts with the close connection between spiritual civilization construction and volunteer service, and explores the specific ways for colleges and universities to introduce volunteer services to promote the smooth development of spiritual civilization construction, hoping to play a certain reference.
\end{abstract}

Keywords: Spiritual civilization construction; comprehensive literacy; colleges and universities; college student volunteer service

The implementation of quality education has led to the continuous development of China's education system reform. In addition to focusing on education, people are gradually realizing the importance of volunteering for students' practical ability, value development, and ideological and moral improvement significance. Therefore, in order to enable students to develop better, through the smooth development of spiritual civilization construction, students can grow into high-quality talents whose values and behavior consciousness meet the social requirements. Through the introduction of volunteer services, students can be trained Psychological qualities can enable them to improve their resilience, communicative ability and stress resistance through the participation of diversified practical activities, and then grow into a pillar of talent for promoting the development of social spiritual civilization with a better mental outlook. .

\section{Close connection between spiritual civilization construction and volunteer service}

\subsection{Harmonious coexistence}

The construction of spiritual civilization as a relatively complex educational content requires colleges and universities in the long-term construction to enable students to grow into pillars of higher spiritual literacy under the guidance of correct values and promote better society. development of. At present, the construction of spiritual civilization in colleges and universities mainly takes patriotic spirit, civilization construction and ideal construction as the main modules, and involves specific contents such as civilization politeness, political literacy, moral level and spiritual values. Volunteer service, as an important activity to train students' ideals, beliefs, practical abilities, and ideological spirit, combined with the construction of spiritual civilization, can not only ensure the comprehensive development of students in the process of harmonious coexistence, but also implement the school's educational effectiveness. At the same time, students will grow into high-quality talents with a high patriotism, civilization literacy, and ideals and beliefs.

Copyright (C) 2020 Yanpeng Gao

doi: $10.18282 /$ le.v9i5.1225

This is an open-access article distributed under the terms of the Creative Commons Attribution Non-Commercial License

(http://creativecommons.org/licenses/by-nc/4.0/), which permits unrestricted non-commercial use, distribution, and reproduction in any medium, provided the original work is properly cited. 


\subsection{Complement each other}

With the in-depth development of the reform of the education system, many colleges and universities will introduce volunteer services into the construction work according to the specific education of the school and the development requirements of students when carrying out spiritual civilization construction activities. Through the participation of volunteer services, students can make specific plans for their future development prospects and growth directions in various practical activities, and through the acquisition of service experience and the improvement of practical ability, they can learn knowledge outside the classroom . This not only allows students to continuously extend their ideological and moral level, but also enables them to develop more comprehensively in a richer spiritual ideology. Therefore, the introduction of volunteer services can effectively promote the education activities of college students who cultivate noble spiritual civilization, and ensure the effective implementation of spiritual civilization education, so that in a complementary role, the two can not only ensure better development of students, but also promote colleges and universities In the wave of development of the times, it has always been in an invincible position.

\section{The Way of Volunteer Service Introducing Spiritual Civilization Education in Colleges}

\subsection{Stimulate students' interest in participation}

College students have developed a sound sense of speculation and behavior, but due to the current academic tasks, blurred future development goals and high employment pressure, students have been unable to adjust their mentality well, leading to many psychological problems Learning has a greater negative impact. If it is not resolved in a timely manner, it will not only seriously affect the physical and mental development of students, but also cause them to go astray in the process of lacking correct guidance. This requires colleges and universities to actively promote the construction of spiritual civilization and carry out the activities smoothly. Combined with the learning needs and interest characteristics of students, students are encouraged to try to read books of mental health type in peacetime, so that they can hint at harmony and stability Release pressure in the environment and form a healthier mentality, so that students can fully mobilize their enthusiasm for volunteering. This will not only enable students to take various forms of voluntary service activities, but also ensure the healthy development of their body and mind under the guidance of healthy emotions, but also enable students to always ensure the smooth improvement of the correct value concept in healthy and upward practical activities, and then subconsciously China guarantees the smooth development of spiritual civilization education.

\subsection{Improve volunteer service settings}

A good volunteer service environment can not only improve students' practical ability and spiritual literacy, but also accelerate the process of spiritual civilization construction in the process of subtlety. Therefore, colleges and universities need to improve the volunteer service settings in accordance with the actual situation of the school. By investing in hardware settings and education funds, they will be able to help the spiritual civilization construction work better. Therefore, the school can develop a column for books on spiritual civilization construction in the library room for students' spiritual phenomena and learning needs, so that students can borrow the books they want at any time when they have reading needs. At the same time, the school should also allocate a corresponding civilized counselor for each major, so that teachers can adjust the content of volunteer services in a timely manner through the learning situation and life attitude of students, helping students to find more targeted in the participation of activities Return to his own state of spiritual civilization, and then grow into a sun-type high-quality professional talent.

\section{Conclusion}

In order for colleges and universities to develop better in the wave of education system reform, schools need to strengthen their teaching level on the one hand, but also need to pay attention to the effective implementation of spiritual civilization construction. Therefore, the introduction of volunteer service can not only enable students to have a better mental outlook in various practical activities, but also effectively improve their comprehensive literacy, and 
then introduce a more positive attitude into future learning and In life, under the guidance of the concept of spiritual civilization, students can gradually grow up to be talents who are in line with the concept of social spiritual civilization.

\section{References}

1. Zhang Honglei. Voluntary Service Platform for Special Education_Exploration and Practice of Ideological and Political Education Work for College Students Based on the Model of "One Heart, Three Integrations and Two Combinations"[J]. Science and Technology, 2020(18):286+295.

2. Yu Shumin, Liu Hongfen, Qiu Weibo. Research on the path of constructing a long-term mechanism for college volunteers under the new era [J]. Journal of Hubei Open Vocational College, 2020, 33(11): 59-60+63.

3. Xiong Zhiyan. Practice and Exploration of Volunteer Service in Colleges and Universities under the Background of Regional League Building__ Taking Wuhan Xigong University Volunteer Service Team as an Example[J]. Education Teaching Forum, 2020(21):230-231. 